\section{SUCCESSFUL PROSTATECTOMY AT NINETY YEARS.}

BY JAMES B. MACALPINE, F.R.C.S. ENG., GURGEON AND SURGEON IN CHARGE OF THE GENITO-URINARY DEPARTMENT, SALFORD ROYAL HOSPITAL.

THE reason for reporting the present case is that it demonstrates that in suitable cases prostatectomy may be successfully performed even in extreme old age.

On March 10 th, 1921, J was asked by Dr. C. H. Ferguson, of Eccles, to see with him in consultation J. H., a male, aged 90 years and 10 months, suffering from prostatic retention.

History.-There had been some slight difficulty in micturition for an indefinite period, together with insignifican nocturnal frequency. On March 7th, 1921, an attack of retention had to be relieved by the catheter, which again had to be passed on three occasions during the next two days; its introduction was particularly painful and difficult, the angle in the prostatic urethra appeared to be very acute.

Examinaiion.-Patient was thin, wiry, very active, and of good intelligence. Temp. $98 \cdot 6^{\circ} \mathrm{F}$., pulse 68 , of good quality, low tension, and regular, though with an occasional intermission ; cardiac sounds normal, lungs healthy. Complexion fresh, appetite good, though he was fastidious as regards his diet. Tongue moist, though somewhat coated; no headache or vomiting; bowels acted regularly; urine had a specific gravity of 1012 , was acid in reaction, contained a fair trace of albumin, and was free from pus and sugar. He sufiered from bilateral senile cataract in an advanced stage.

Abdomen.-Examination showed a thin wall of good muscular development considering the patient's age. The bladder formed an obvious swelling in the hypogastrium : palpation of the renal angles revealed no tenderness or increase in size of the kidney. Rectal examination showed a prostate of medium size and soft consistency.

Patient was removed to a nursing home; on his arrival 2 catheter was introduced and in the first 24 hours 92 oz. of urine were slowly drained away. After this the average secretion of urine fell to about 30 or. in the 24 hours. When the catheter was removed he was quite unable to urinate naturally. He was under observation until March 18th, and remained comfortable, with normal temperature and pulse and reasonable appetite. The coating of the tongue disappeared. On the 18th an attempt to re-insert the catheter failed completely, in spite of considerable perseverance, and the use of a varied selection of instruments. As the bladder was distended I was faced with the necessity of making a decision as to the best method of emptying it in this particular patient. The desirability of operation had to suprapubic drainage was explained and discussed, but the patient and his relatives were strongly opposed to it, and more than willing to face the added risk of a prostatectomy.

Operation.-Anæsthesia was induced by Mr. J. Ghosh, and as speed was desirable, the bladder was quickly opened, a prostate of medium size easily enucleated and the bladder closed around $\mathrm{my}$ special suprapubic drainage-tube. (The total length of absence of the patient from his bed, including transit, anæsthesia, and operation, was 16 minutes.) Bleeding was very slight, and shock practically absent. The evening temperature was $97 \cdot 6^{\circ}$, the pulse 60 , and the following morning $99 \cdot 4^{\circ}$ and 100 respectively. After that convalescence was uninterrupted. For the first 12 days the average urinary output was $25 \mathrm{oz}$; after that there was oliguria, only $60 \mathrm{oz}$. altogether being passed in five days, but the patient showed no symptoms of the retention of urinary products. At the end of this time recovery set in; by the end of the fourth week the output was 28 oz. per diem. The small quantity of fluid passed during this period may in part be explained by the very small stature of the patient, and in part by a belief on his part that to take fluids was injurious to him-a helief very difficult to dislodge, and apparently a survival from the days when he suffered from retention. It was, of course, partly due also to diminished renal function. Urine was passed naturally on the fortieth day, and the patient left the home a few days later.

In June he wrote to me from North Wales: "I am progressing wonderfully, even so as to satisfy you. I think I shall take refuge with my daughter in California." In November be unfortunately contracted influenza, to which he succumbed after a few days' illness, there being no urinary trouble.

\section{Remarks.}

I have not been able to find in the literature a record of a prostatectomy at so advanced an age. Freyer's series of 1550 cases is usually referred to as being remarkable for containing many particularly aged patients; the greatest age in this series is a patient "in his ninetieth year." 1 Sir J. Thomson Walker in 1914 reported the maximum age in his series at 86 . Legueu refers to the results obtained by Freyer, even in cases of extreme old age, which suggests that he has not himself performed operations on such aged patients.

Excessive age is naturally usually regarded as a contra-indication to prostatectomy. Tenney and Chase collected details regarding 816 cases of prostatectomy which had a fatal issue, and prepared a table indicating relationship of age to mortality, showing an increasing percentage of deaths with increasing age.
Age in years.

$50-59$

$60-60$

$70-79$

80 and over
$5 \cdot 3$
$9 \cdot 5$

$15 \cdot 0-33$

50
Percentage of deaths.

In contrast with this statement, however, is one by Thomson Walker :-

" Old age does not itself contra-indicate prostatectomy. The mortality does not increase pari passu with the age In 83 cases the death-rate was greater between the ages of 55 and 60 than between 66 and 70 , or over $75 \ldots$ The feeble resistance of .... ased patients must, however, bo borne in mind . . . ." \&c.

In this particular case I would willingly have shirked the responsibility had an alternative method presented itself. However, the result justified the measures employed. My patient was well-preserved, his cardio-vascular and renal systems were good; these facts, together with a high speed in operating, achieved the happy result.

\section{Clinital a dotes:}

MEDICAL, SURGICAL, OBSTETRICAL, AND THER APEUTICAL.

\section{A CASE OF \\ MULTIPLE CONGENITAL DEFECT.}

\section{By Kenneth M. Purves, M.B., Ch.B. Edin.,} ASSISTANT MEDICAL OFFICER, BAGTHORPE INFIRMARY, NOTTINGHAM.

THE subject of these notes was a full-term male infant born in the Lock ward of the Bagthorpe Infirmary, Nottingham. The mother was a feebleminded single woman aged 20 , admitted early in pregnancy with primary and secondary syphilitic manifestations which rapidly cleared up under treatment, the Wassermann being negative for three month before confinement. The father was an elderly gipsy.

The child showed no evidence of active syphilis and its blood test was negative. At birth it was found that the anus was absent, being represented by a slight pigmented dimple within a ferv hours signs of pressure became manifest-viz, bulging of perineum when the child cried, cdema of the scrotum and groins, prominence of the mesial scrotal vein, and general cyanosis. An incision was made through the anal dimple, the rectum brought down and opened, and when the meconium had escaped the mucous edges were united to the skin edges. The pressure symptoms rapidl y disappeared, the wound healed by first intention, and the artificial anus functioned satisfactorily.

The cyanosis, however, persisted, and although the child sucked well, cried lustily, and gained weight the cyanosis, together with the weakness of the pulse, faintness of the heart sounds, and shallowness and rapidity of respiration raised the suspicion of congenital heart disease, though no confirmatory evidence was forthcoming.

At the end of about three weeks the child ceased to thrive, would not suck, and became very lethargic. The cyanosis increased, there was marked cedema of the arms and legs, the temp, sank to $95^{\circ} \mathbf{F}$, and a large swelling was observed in the epigastrium. Death took place on the twenty.fourth day.

\footnotetext{
1 THE IANOET, 1913, i., 1018.
} 
Post Mortem.-The following defects were found :-

1. Absence of the anus as described above.

2. Complete transposition of viscera; the thoracic and abdominal contents were a mirror image of the normal arrangement. The heart lay in the right side of the thorax and its left auricle and ventricle corresponded to the normal right and vice-versa. The aorta ascended to the second left costal cartilage and then arched backwards and to the right. The innominate artery was on the left and the right common carotid and subclavian arteries arose separately from the aorta. The right lung had two lobes and the left three. The stomach lay under the right vault of the diaphragm with the pylorus crossing the vertebral column, on the left of which lay the duodenum. The normal positions of the liver and spleen were reversed, the pancreas crossed from right to left, and the mesentery extended from the right side of the vertebral column downwards and to the left. The crecum and appendix occupied the left iliac fossa and the sigmoid colon the right.

3. Persistence of the foramen ovale, which allowed the passage of a closed Spencer-Wells forceps from one auricle to the other. No other defects in the normal structure of the heart were found. The closing membrane of the foramen ovale appeared to be absent or very defective.

4. Great dilatation of the stomach causing the epigastric tumour observed before death. The pyloric sphincter was hypertrophied, this being apparently the cause of the dilatation. The lower end of the osophagus shared in the dilatation. The child only vomited once shortly before death.

The lungs appeared to be fairly well expanded, but were congested and showed scattered patches of consolidation, chiefly in the upper lobes. This bronchopneumonia must have been largely due to the cardiac defect, as the child had received particularly good nursing and care from birth.

\section{HAMANGIOMA OF LARYNX.}

\section{By J. B. Cavenagh, M.B., Ch.B. Oxf.}

THE following case illustrates the importance of a thorough examination of the larynx in any case of prolonged hoarseness.

The patient, a married man of 32 , with good family history and sound general health, began to complain of hoarseness and cough in 1916. He was treated by his doctor for these symptoms, but in spite of all efforts the hoarseness persisted. In May, 1921, the condition was pronounced tuberculous, as the result of which the patient was sent to a sanatorium, where he remained for several months; but on no occasion was the medical officer in charge able to discover any evidence of tuberculosis, either in the lungs, larynx, or sputum.

At the end of October, 1921, the patient was sent to me for an opinion. The man looked ill, had lost some weight, and was worried and depressed about the diagnosis; the voice was gruff and harsh, with momentary periods of aphonia. Examination with a mirror showed signs of mild chronic laryngitis, and, situated over the anterior commissure a pedunculated growth the size of a small bean, which prevented proper approximation of the cords on phonation.

Operative treatment was naturally recommended, and on Dec. 2nd, under general anæsthesia, I removed the grow th by the direct method. On microscopical examination it proved to be a hæmangioma. The patient was kept on silence for two weeks; three weeks later finds him with a good clear voice and fit in every respect.

One cannot help thinking what time and trouble might have been saved, for all those concerned, had the larynx been carefully examined at a very much earlier date.

BirminghaM Eye Hospital. - At the annual meeting held on March 16th the report stated that the ordinary expenditure was $114,134118,7 d$., or $£ 848$ less than the previous year. The ordinary income was $\mathcal{1} 12,875$, being \pm 298 more than last year. There was a reduction in the receipts from annual subscribers. The number of patients admitted to the public wards was 1539 , the average length of stay being 15.9 days, as compared with 14.9 days in 1920. In the private wards 95 patients were treated. In the out-patient department there were 69,100 attendances, the average daily attendance being 225 . Of the 69,100 the casualties numbered 16,007. Operations in the in-patient department were 1012 and in the out-patient department 659. Chief among these were 309 for cataract, 87 for glaucoma, 137 for strabismus, 58 for removal of foreign bodies by the electromagnet, and 106 for removal of the eye.

\section{attedical Soctetirs.}

\section{ROYAL SOCIETY OF MEDICINE.}

\section{SECTION OF SURGERY:}

\section{SUBSECTION OF PROCTOLOGY.}

The After-Results of Colectomy.

A mentina of this subsection of the Royal Society of Medicine was held on March 22nd, with Sir C. Gordon-W Atson, the President, in the chair, when Mr. E. R. FuInT opened a discussion on the AfterResults of Colectomy (partial and complete) performed for Colon Stasis.

Colectomy only Successful in Selected Cases.

Mr. Flint distributed circulars embodying the results of operation at Sir Berkeley Moynihan's clinic at Leeds up to the end of 1920, the contents of which may be summarised as follows:-

Sixty-eight cases were operated upon: (1) In 60 cases primary hemicolectomy was performed, with a mortality of two (one from shock and one from pulmonary embolism) (2) in eight cases ileosigmoidostomy was performed, with no deaths. Of Group 137 cases had been traced : In 15 of these the result was " good" or "very good." There had been a gain in weight of from $1 \frac{1}{2}$ to 4 st.; there was no indigestion or flatulence, the bowels acted normally, and the patients were able to lead normal lives. In all these cases the cæcum at operation was full, blue, " soggy," dependent, and obstructed mechanically. (This form of cæcum was seen in 20 cases in all.) In 16 the result was fair. The general health was improved, but there were occasional attacks of heartburn and indigestion. None of these patients had been restored to full good health. In six the result was " poor." These patients were still ailing, thin, miserable, and unfit. All were believed to be examples of "deficiency disease." Of Group 2 six cases were traced : In two the result was "good," in two the result was "fair" or only "slightly improved," and in two the result was " poor." In a large proportion of both groups of cases there had been previous operations, such as appendicectomy, nephropexy, and various pelvic operations-oöphorectomy, ventrifixation, \&c.-without benefit.

Mr. Flint said that the object of his paper was to show that colectomy was only successful for a few selected cases of intestinal stasis, which was not now regarded as a disease in itself but rather as a part of a general nutritional disorder. Metchnikoff and Sir Arbuthnot Lane held the view that the colon was a degenerate, useless, and often harmful structure in man. But Sir Arthur Keith had pointed out that its total glandular structure exceeded that of the pancreas and its total muscle tissue exceeded the biceps of a blacksmith ; and he (Mr. Flint) added that its vascular supply was lavish, from which it would hardly appear to be a degenerate organ. One of the important functions of the colon was the absorption of fluid, and after colectomy this function was taken over probably by the terminal ileum, with the result that the fæces were inspissated as before, since the body must have fluid, and stasis returned. The result of colectomy would therefore appear to be that the trouble was shifted further back. To be justifiable, the operation for removal of an important organ such as the colon should result in a high proportion of curesand that high proportion was not attained in the cases he was discussing. The best results were obtained when there was chronic mechanical interference by constricting bands across the ascending colon usually in the neighbourhood of the hepatic flexure, and microscopic examination revealed an alteration of the neuromuscular mechanism sufficient to account for the absence of propelling power of the gut. The colon and cæcum in these cases were thick, "soggy," voluminous, and full of pultaceous fæcal material. In the less successful cases or failures this condition was rarely seen; in these cases change had probably occurred in other organs such as the liver.

\section{Is Stasis a Deficiency Disease?}

Mr. Flint said that Sir Berkeley Moynihan attributed his failures to the fact that the colon was only one of 